How Does Perseverance of Effort Influence the University Outcomes of Historically Underrepresented Students?

\author{
Kevin Fosnacht \\ Keeley Copridge
}

Indiana University, Bloomington

Forthcoming in L. van Zyl, C. Olckers, \& L. van Der Vaart (Eds.) Perspectives on Grit: Contemporary Theories, Assessments, Applications and Critiques. Springer. 


\title{
How Does Perseverance of Effort Influence the University Outcomes of Historically Underrepresented Students?
}

\begin{abstract}
Grit has become a popular concept in the education field and is characterised by consistency of interest and perseverance of effort. This study focuses on one dimension of grit, perseverance of effort, to examine if it has compensatory effects for historically underrepresented students. Using a large, diverse sample of undergraduates, the results indicate that perseverance of effort has a stronger relationship with some process indicators of student learning than for traditional students. Additionally, we did not observe any stronger relationships for traditional students relative to nontraditional populations. Consequently, the results suggest that perseverance of effort can have compensatory effects that can help historically underrepresented students overcome obstacles to student success.

Keywords: grit; perseverance of effort; non-cognitive traits; student engagement; higher education; racial differences
\end{abstract}




\section{How Does Perseverance of Effort Influence the University Outcomes of Historically Underrepresented Students?}

Grit has become a popular concept in the education field that proponents believe could explain why some students do not succeed in their educational pursuits (Del Giudice, 2014; Duckworth, Peterson, Matthews, \& Kelly, 2007; Engber, 2016). Grit is defined as the "perseverance and passion for long term goals" and is a non-cognitive personality trait (Duckworth et al., 2007). This trait contains two constructs: perseverance of effort and consistency of interest (Duckworth, 2016). While grit has various proponents, others have criticised grit as a repackaged concept (Credé, Tynan \& Harms, 2016) and a way to justify inequality in our society (Gonzales-Stokas, 2015; Ris, 2015).

Due to the drastically different opinions on the concept of grit, it is imperative to evaluate how grit influences student outcomes empirically. This study follows up on a previous effort to examine the validity of grit for a large and diverse sample of undergraduates (Fosnacht, Copridge, \& Sarraf, 2019). It found partial support for the validity of grit as one of its dimensions, perseverance of effort, was positively associated with a variety of postsecondary outcomes; however, its construct validity needs improvement. Additionally, it found that grit did not exhibit measurement invariance by race, sex, parental education, and class level. This finding indicates that the measurement of grit is not biased against historically marginalised groups, in contrast to the critiques of Gonzales-Stokas (2015) and Ris (2015). Therefore, we extend our previous analyses and seek to examine if perseverance of effort has the potential to provide compensatory effects for historically marginalised groups.

\section{Literature Review}

The emergence of grit has become a popular concept in the education system. The U.S Department of Education identified grit as one of the non-cognitive factors that were critical for 
success in the $21^{\text {st }}$ century and beyond test scores and intellect (Shechtman, DeBarger, Dornsife, Rosier, and Yarnall, 2013). Grit, a concept developed by Angela Duckworth, is defined as the “perseverance and passion for long term goals" (Duckworth, Peterson, Matthews, \& Kelly 2007). Grit is a non-cognitive personality trait that includes two lower-order features: perseverance of effort and consistency of interest (Duckworth, 2016; Duckworth et al., 2007). Perseverance of effort is an individual's tendency to work hard regardless of setbacks and obstacles (Duckworth et al., 2007; Duckworth, 2016). Consistency of interest is the propensity not to change goals and interest frequently (Duckworth et al., 2007; Duckworth, 2016). These two constructs work together to positively influence an individual's behaviour and attitude to attain their long-term goals. Grit is often compared to other personality traits such as the Big Five. However, grit differs as it focuses on more long-term goals that require effort and interest. The lack of correlation with intelligence shows that this trait can potentially explain why some students succeed, while others fail (Duckworth et al., 2007; Duckworth, 2016).

Studies have found that grit significantly impacts successful outcomes after conditioning for IQ (Duckworth et al., 2007; Eskreis-Winkler, Duckworth, Shulman, \& Beal, 2014). . Duckworth and colleague's (2007) study examined the influence of grit and high-achieving populations such as West Point cadets and Scripps Spelling Bee finalists. The study found that grit successfully predicted attrition among the cadets who completed an intense training program and the number of hours Spelling Bee finalists practised.

In the undergraduate setting, studies have shown a positive correlation between grit and students e-learning success and academic outcomes for at-risk populations. Aparicio and colleagues (2017) examined grit's impact on e-learning systems success and satisfaction. The findings from this study showed that grittier students were more successful with e-learning 
systems and reported greater satisfaction than less grittier students. The impact of grit reaches a diverse demographic population as Hodge, Wright, and Bennet (2017) study examined the influence of grit on undergraduate student engagement and productivity. The results from this study found that students who were the first in their family to go to college were associated with increased levels of grit.

Moreover, Eskreis-Winkler and colleagues (2014) examined the influence of grit and retention in various settings like the military, the workplace, school, and even marriage. Results from this study showed that within the military setting, grittier soldiers were more likely to complete a grueling Special Forces selection program. An analysis of grit and high school graduation found that grittier students were more likely to graduate from high school. Lastly, grit influenced the likelihood of staying married, as the results showed that men with higher levels of grit were more likely to remain married (Eskreis-Winkler, 2014).

\section{Grit and University Students}

Research on grit has examined its influence on the university student population and has found some promising results. Studies on grit and its constructs have found its impact on student's persistence and success among difficult, long-term tasks (Duckworth et al., 2007; Duckworth \& Quinn, 2009). Among university students, grit has been positively correlated with academic adjustment, higher grade point average, increased satisfaction, increased facultystudent interaction, and co-curricular engagement (Bowman, Hill, Denson, \& Bronkema, 2015). Grit influences students' self-regulated learning as Wolter and Hussain's (2015) study found that grittier students were less likely to procrastinate on academic tasks. Moreover, Weisskirch's (2018) study examined how self-esteem and grit influence student's estimated and final grade, use of learning strategies, and attitudes about lifelong learning. The findings from this 
study found that the perseverance of effort construct and self-esteem predicted a student's anticipated course grade.

Within the $20^{\text {th }}$ and $21^{\text {st }}$ century, the United States has become significantly more diverse (Turner, Gonzalez, \& Wood, 2008). The increase in diversity within the country has affected the American postsecondary education system. In response to the change in U.S. university student demographics, research has connected grit with sociocultural factors such as student's race, gender, and parent's educational status. Research examining these factors and grit is essential as minority students remain underrepresented, unsupported, and unsuccessful in attaining their educational aspirations relative to traditional students, students who enroll in college after graduating high school and fall between the ages of 18 and 22 (Adams \& Corbett, 2010; Harper \& Hurtado, 2007; Milem, Change \& Antonio, 2005).

Grit has cross-cultural applicability as it has examined its influence on racial/ethnic groups, gender, and first-generation university students. Research shows that grit is associated with mental health, academic success and overall life satisfaction for these demographics (Datu, Valdez, \& King 2015; Strayhorn, 2014; Vela, Lu, Lenz, \& Hinojosa, 2015; Wolter \& Hussain, 2015).

\section{Grit and Race/Ethnicity}

Research examining grit and Black students is sparse but highlights the impact grit has on this demographics' academic success and retention (Strayhorn, 2014; Yates, 2015). Strayhorn's (2014) study examined grit's influence in the academic success of black male students attending a four-year, Predominately White Institution (PWI). Results from this study found that not only did grittier black males students have higher grade point averages in the university, but increased 
high school grade point averages and ACT scores compared to their less gritty counterparts (Strayhorn, 2014). Further analysis of the data showed that grit was a positive predictor of their university grades even after controlling variables such as age, year in school, engagement activities, transfer status, major aspirations, and prior achievements (Strayhorn, 2014).

Yates and colleagues' (2015) examined how grit influenced African American teachers' academic retention. The results from this study showed that the participants had high grit scores, yet there was a weak or no significant relationship between the participants' age, GPA, and firstgeneration status and grit. Qualitative findings showed that African-American male pre-service teachers acquired their grit from three sources: their family, life circumstances, and spirituality (Yates et al., 2015).

Studies on grit within the Asian community have focused on undergraduate Asian students enrolled in American and international universities. Research examining grit and Asian university students found that grit positively influenced life satisfaction amongst Filipino students (Datu et al., 2015). Amongst Thailand and Chinese undergraduates, there was a negative relationship between grit and mental health (Zhang, Mou, Tong, \& Wu, 2018). Moreover, grit positively influenced the achievement goals of Chinese undergraduate students (Chen, Ye, Hangen, 2018).

Further analysis of the influence of grit and its constructs, consistency of interest and perseverance of effort, showed that grit predicted four forms of achievement goals in different ways. In this comparative analysis of four forms of achievement goals between American and Chinese undergraduate students, Chen, Ye and Hangen (2018) found that consistency of interest negatively predicted performance-avoidance goals, one of the four forms of achievement goals. Perseverance of effort positively predicted all four goal types with a stronger association among 
mastery-approach and performance-approach goals compared to the mastery-avoidance and performance-avoidance goals (Chen et al., 2018). Moreover, Slick and Lee's (2014) study examined the influence of grit and attrition for international students enrolled at a Korean university and found a negative correlation between grit and dropping out of university (Slick \& Lee, 2014).

\section{Grit and Gender}

Scholarship examining the influence of grit and gender have shown mixed results. Duckworth and Quinn's (2009) study validating the Short Grit scale with Scripps Spelling Bee finalists found no significant relationship between gender and grit. Bazelais, Lemay, and Doleck (2016) came to a similar conclusion using a sample of students enrolled in a science class.

In contrast, studies have shown that females from diverse backgrounds have more grit than their male counterparts (Christensen \& Knezek, 2014; Guerro, Dudovitz, Chung, Dosanijh, Wong et al., 2016; Jaeger, Freeman, Whalen, \& Payne, 2010). Guerrero and colleagues' (2016) study examined the association between grit and health behaviours among at-risk Latino adolescents. They found that grit was slightly lower among Latino males relative to Latina females (Guerro et al., 2016). This was confirmed in Jaeger and colleagues' (2010) study that sought to examine the grit of first-year engineering students. Their review of the grit constructs found that the most significant difference between gender was with the consistency of interest construct. This insinuates that females were more likely to maintain interest in their major than their male counterparts. Lastly, Christensen and Knezek’s (2014) study examined how grit differed based on gender and found that females had significantly higher grit compared to their male counterparts.

\section{Grit and Parental Education Status}


Often studies examining grit have demographics that are first-generation but focus on more salient factors such as race, gender, and its impact on grit (O’Neal et al., 2016; Strayhorn, 2014). Research has shown mixed results on how grit influences first-generation college students (Almeida, Byrne, Smith, Ruiz, 2019; Hodge et al., 2017;Midkiff, Langer, Demetriou \& Panter, 2016; Verdin, Godwin, Kirn, Benson, \& Potvin, 2018). For example, Hodge and colleagues (2017) examined the influence of grit and academic productivity with 395 Australian university. The study found that students who are first-generation were associated with having more grit than their second-generation counterparts (Hodges, et al., 2017). The positive influence of grit was further confirmed by Verdin and colleagues' (2018) study which examined how first-generation students' engineering identity and sense of belonging was fostered by grit. Results from the structural equation modeling found that the consistency of interest construct explained $97 \%$ of the variance of the student's sense of belonging in the engineering field, while perseverance of effort explained $76 \%$ of the variance of the student's engineering identity.

Recognizing the importance of social capital on student educational outcomes, Almeida and colleagues (2019) sought to examine the relationship between first-generation college student's grit and social capital in their academic success. In this study, first generation juniors and seniors completed a survey inquiring about their mentoring and support systems, GPA, standardized test scores and demographics in addition to the Grit Scale. The results from an ordinary least square regression model showed that grits and its two constructs, consistency of interest and perseverance of effort were not found to be significant predictors of the student's grade point average. However, access to social capital was predictive of a student's grade point average as each additional faculty or staff who a first-generation student received informational 
support was associated with a .003 unit increase in the college grade point average (Almeida et al., 2019). Moreover, scholars encourage more research on the validity and reliability of grit and first-generation students as Midkiff and colleague's (2016) study found that the constructs of grit, consistency of interest and perseverance of effort, did not load into the higher order construct of grit.

The mixed results on the influence of grit on first-generation students warrants the need for further research. Additionally, people are multi-faceted individuals who have multiple intersecting identities that consist of privileges and oppression that influence their worldview. Thus, the linear construct of grit is often criticised for being unable to fully incorporate the experiences of gendered, classed, and raced identities.

\section{Theoretical Framework}

Ajzen's Theory of Planned Behavior (1991) guided our investigation into examining if the relationship between perseverance of effort and student outcomes varied by student characteristics. The Theory of Planned Behavior postulates that an individual's behaviour is influenced by their intention to carry out the behaviour and their perceived behavioural control. The intention to engage in a behaviour is predicted by an individual's attitude towards the behaviour, subjective norms, and perceived behavioural control. Perceived behavioural control is an individual's perception of ease or difficulty in performing the behaviour of interest and is closely related to Bandura's (1977) self-efficacy concept. It is important to note that this perception varies across situations. For example, a student's engagement in seeking tutoring may relate to their belief in their high school preparation and their ability to retain the material. Attitude towards the behaviour is an individual's evaluation (positive or negative) of the behaviour. An example of attitude for this study is if a first-year student expects attending office 
hours to be beneficial, then this person is more likely to attend office hours. Subjective norms are defined as perceived social pressures to perform or not perform the activity. These social pressures are from other individuals or communities that are important in the individual's life. Thus, the social pressures of being successful from a student's family or community may influence a student's desire to engage in educationally beneficial activities. Alternatively, social norms at their institution may influence students to study collaboratively with friends.

The Theory of Planned Behavior has been incorporated into numerous studies to assist in understanding and modifying student behaviour. One such behaviour that has been investigated is student engagement where Siragusa and Dixson (2009) used the theory to examine undergraduate students' engagement with Information Communication Technology. Burns, Houser, and Farris (2018) incorporated this theory to examine how teacher confirmation or feedback influences an undergraduate student's behavioural intention to communicate with their instructor. Numerous studies using this theory have examined the behavior intentions of university students ranging from drinking (Collins \& Carey, 2007), physical activity (Blanchard et al., 2008), and the use of social networking websites (Pelling \& White, 2009).

For this study, we seek to examine the constructs of Theory of Planned Behavior (Attitude, Subjective Norms, and Perceived Behavioral Control). This theory will be used to examine how the perseverance of effort construct influenced historically underrepresented student's engagement in educationally purposeful activities compared to their white counterparts.

\section{Purpose}

This study follows up on previous work investigating the validity of the Short Grit Scale, which found a positive relationship between perseverance of effort and a variety of process 
indicators of student success (Fosnacht et al., 2019). In the current study, we sought to investigate if the grit construct has the potential to provide compensatory effects in students' engagement, self-perceived gains, time spent studying, and GPA for historically marginalised groups. In other words, does grit have a stronger relationship with essential outcomes for historically marginalised populations relative to traditional student populations? If grit does provide compensatory effects, it may be a pathway to help improve outcomes for historically marginalised groups if grit is a malleable trait (Duckworth, 2016).

\section{Methods}

\section{Data}

The study used data from the 2016 administration of the National Survey of Student Engagement (NSSE). NSSE is a large, multi-institutional study of undergraduates that inquires the frequency of student engagement in a variety of educationally beneficial activities, student time use, perceptions of the campus environment, and other similar measures. In 2016, students attending a subset of institutions received an additional item set that included a slightly modified version of Duckworth and Quinn's (2009) Short Grit Scale (item wording was lightly edited to comport with the core NSSE instrument). Thus, we focused our analyses on students from these 38 institutions that received the additional items. Our sample included 4,668 first-year and 7,082 senior students that responded to both NSSE and the additional items. The response rates were $21 \%$ and $24 \%$ for the first year and senior samples, respectively.

The students included in our analyses were relatively diverse. About two out of three students were female. Slightly less than $57 \%$ of the respondents were White, while Asian/Pacific Islander, Black, Latina/o, multi-racial, and international students represented $6 \%, 11 \%, 12 \%$, $7 \%$, and $5 \%$ of the respondents, respectively. About half of the students had a parent who 
completed a bachelor's degree. Over $40 \%$ of the respondents attended a public institution. Half of the respondents were enrolled at institutions with a Barron's rating of "competitive". The majority of students attended master's universities, one in four students attended doctoral universities, baccalaureate universities comprised $15 \%$ of the sample, and $5 \%$ of the respondents attended a special focus institution.

The key variable in our analyses was a modified version of Duckworth and Quinn's perseverance of effort subscale (see Fosnacht et al., 2019 for more detail). We focused on this variable as it was previously found to be related to a variety of outcomes, in contrast to the consistency of interest subscale (e.g., Bowman et al., 2015; Credé, 2016; Fosnacht et al., 2019; Muenks et al., 2017). Perseverance of effort represents students' attitudes in our theoretical model. Our dependent variables were process indicators of student learning and development captured on the main NSSE instrument. These variables include 9 of the 10 NSSE Engagement Indicators (Effective Teaching Practices was excluded as it focuses on faculty, not students), NSSE's perceived gains scale, time spent preparing for class, and self-reported grades.

Prior research has found that these measures predict students' learning and college retention and are process indicators of student success (Kuh, Kinzie, Cruce, Shoup, \& Gonyea, 2006; National Survey of Student Engagement, n.d.; Pascarella, Seifert, \& Blaich, 2010). Additionally, they are direct or indirect measurements of behavioural outcomes in the Theory of Planned Behavior. We standardised perseverance of effort, and the dependent variables to all have a mean of 0 and a standard deviation of 1 . Three student characteristics were also of focus in this study that indicated membership in a historically marginalised class: race, sex, and parental education. These characteristics were chosen to represent subject norms from students' identity-based community. We collapsed these variables into binary variables to ensure adequate 
statistical power as, despite our large sample size, many subgroups contained less than 100 students. To control for other factors related to engagement, we also utilised data on the following student characteristics: standardised test score (SAT/ACT), academic major, Greeklife participation, age, athletics participation, transfer status, part-time status, educational aspirations, and on-campus residency. These variables have been previously correlated with student engagement (National Survey of Student Engagement, 2010; n.d.)

\section{Analyses}

We began our analyses by comparing perseverance of effort by our characteristics of interests: sex, parental education, and race, using two-group t-tests. Next, we fitted a series of fixed-effects regression models that predicted each of the dependent variables using perseverance of effort and the student characteristics described in the data section. These models included institution-specific fixed-effects that allowed us to control for both observable and unobservable institution-specific factors. The institution-specific fixed effects allowed us to control for the subjective institutional norms in the Theory of Planned Behaviour. For each dependent variable, we subsequently fit an additional model that added an interaction term between race and perseverance of effort. The interaction term allowed us to assess if the relationship between perseverance of effort and the dependent variable varied by race. We repeated this step for sex and parental education. Finally, if the coefficient associated with an interaction term was significant at $p<.05$, we then graphed the predicted values of the dependent variable by perseverance of effort and the characteristic of interest when all other covariates were held at their mean. These charts allowed us to quickly interpret the interaction term and determine if perseverance of effort has compensatory effects for historically marginalised groups. We repeated all the analyses above for both first year and senior students. 


\section{Limitations}

Before presenting the study's results, readers should keep some limitations in mind when reviewing the results. First, our dependent variables are process indicators of student learning and development and do not directly measure student learning. Second, the grit scale may be subject to social desirability bias, thus biasing our results. As this study was a secondary analysis of pre-existing data, we were unable to include variables that represented the perceived behavioural control portion of our theoretical model due to a lack of data. Fourth, while our sample is relatively diverse in terms of students and institutions, it is a convenience sample that was not designed to replicate the national population of undergraduates. Therefore, caution should be applied when generalising the results to all undergraduates.

Additionally, our results are correlational and not causal as it is not possible to randomly assign students a non-cognitive trait. Finally, while we hypothesised that the relationship between perseverance of effort and student outcomes would vary by student characteristics, both theory and previous research did not identify specific outcomes that might be subject to this effect. Consequently, we took an exploratory approach that examined a variety of outcomes. A downside of this approach is a high probability of Type I error, where we falsely identified an effect as significant. We considered using adjustments for multiple comparisons like the Bonferoni correction but decided against their use. Effect sizes such as 0.05 SDs, considered trivial in disciplines like psychology, are considered medium in education research (Kraft, in press). Adjusting the significance level for multiple comparisons would increase the probability of Type II error (false negatives), which is a greater validity threat to this type of study than Type I error (Nakagawa, 2004). Additionally, as this study is exploratory, the results should be confirmed in a future study before influencing practice, limiting the risk of Type I error. 
Furthermore, in this study, we are less concerned with the family-wise error within a specific dependent variable than detecting trends across dependent variables, thus a Bonferoni-correction is not appropriate in this scenario (Perneger, 1998).

\section{Results}

\section{First-year students}

Using two-group $t$-tests, we observed a significant difference in perseverance of effort scores between female $(M=0.06, S D=0.97)$ and male $(M=-0.11, S D=1.04 ; t(4663)=5.35, p$ $<.001)$ first-year students. We did not observe a significant difference between White $(M=0.00$, $S D=0.97)$ and non-White $(M=-0.00, S D=1.03 ; t(4476)=0.12, p=.901)$ first-year students. Similarly, we did not observe a significant difference between first-generation $(M=0.01$. $S D=1.03)$ and non-first-generation students $(M=-0.00, S D=0.98 ; t(4501)=0.29, p=.769)$.

Table 1 presents the relationship between perseverance of effort and our dependent variables, conditioned on other student and institutional characteristics. Perseverance of effort was positively and significantly related to all of our dependent variables. The magnitude of the coefficients ranged between 0.14 for Discussions with Diverse Others and 0.33 for Learning Strategies. Thus, a standard deviation change in perseverance of effort was expected to result in a 0.33 SD change in Learning Strategies, holding constant other factors. Overall, the results demonstrate that perseverance of effort is positively correlated with engagement in a variety of domains, perceived gains, time spent preparing for class, and GPA.

Table 2 summarises the results indicating if the relationship between perseverance of effort and the dependent variables significantly varied by race, sex, and first-generation status. This relationship was assessed by including interaction terms between perseverance of effort and the characteristic of interest into the model. The interaction terms between race and 
perseverance of effort were only significant at $p<.05$ for Discussions with Diverse Others.

Significant interaction terms were found between sex and perseverance of effort for HigherOrder Learning and time spent preparing for class. Additionally, significant interaction terms were observed between first-generation status and perseverance of effort for Reflective and Integrative Learning and GPA.

Figure 1 plots the predicted values for Discussions with Diverse Others by race and perseverance of effort. The figure shows that the relationship between perseverance of effort and Discussions with Diverse Others is stronger for non-White students than for White students. Additionally, it shows that non-White students with high levels of perseverance of effort will engage in more frequent Discussions with Diverse Others than White students, with the opposite being expected for students with low levels of perseverance of effort.

Figure 2 contains the same plot, but for the Higher-Order Learning and time spent preparing for class outcomes and sex. The partial correlation between perseverance of effort and Higher-Order Learning is stronger for females compared to males. The bottom panel of the figure shows a similar relationship for time spent studying and perseverance of effort by sex.

Figure 3 shows the interaction plots for first-generation university status. It demonstrates a stronger relationship between Reflective \& Integrative Learning and perseverance of effort for first-generation students than for non-first-generation students. Similarly, the bottom panel demonstrates a stronger relationship between GPA and perseverance of effort for first-generation students relative to the non-first-generation peers. While not shown, the interaction term for firstgeneration status and perseverance of effort on our Higher Order Learning measure nearly met our threshold for statistical significance $(p<.05)$. The results mirrored the results for the other two interactions for first-generation university status. 


\section{Seniors}

Using two-group $t$-tests, we observed a significant difference in perseverance of effort scores between senior females $(M=0.07, S D=0.97)$ and males $(M=-0.12, S D=1.04 ; t(5229)=7.54$, $p<.001)$. We did not observe a significant difference between White $(M=0.00, S D=0.98)$ and non-White $(M=-0.01, S D=1.02 ; t(5972)=0.57, p=.572)$ seniors. However, we did observe a significant difference between first-generation $(M=0.08 . S D=0.95)$ and non-first-generation seniors $(M=--0.08, S D=1.04 ; t(6894)=6.94, p<.000)$.

The main effect results for perseverance of effort in the senior population mirrored the findings for first-year students. Perseverance of effort was positively and significantly related to all of our dependent variables when other student and institutional characteristics were held constant. The magnitude of the relationships varied from 0.11 for Quality of Interactions to 0.25 for GPA. Thus, a SD change in perseverance of effort is expected to result in a quarter SD change in GPA. While the senior results were similar to the first-year results, the first-year results were typically slightly higher than the senior coefficients.

Table 2 contains the significance values associated with the interaction terms between perseverance of effort and the three demographic groups studied. We observed three significant interactions at $p<0.05$ for race/ethnicity, one for sex, and two for first-generation status in our senior sample. Figure 4 plots the relationship between Reflective \& Integrative Learning and perseverance of effort by race. The slope of the line is significantly steeper for non-White students than White students. The middle and bottom panels also demonstrate a similar finding for Quantitative Reasoning and Discussions with Diverse Others in that the estimated relationships are steeper for non-White students than for White students. 
Figure 5 demonstrates the sole significant interaction effect observed by sex. The partial correlation between Student-Faculty Interaction and perseverance of effort was stronger for females than males. The top panel of Figure 6 shows that the relationship between perseverance of effort and Supportive Environment was steeper for first-generation students than their peers who had a parent who completed university. Finally, the bottom panel of Figure 6 shows a similar relationship for Student-Faculty Interaction as the relationship for first-generation students was stronger than for non-first-generation students.

\section{Discussion}

Grit has captured the attention of the education community, both proponents and detractors alike. Consequently, it is imperative to better understand the utility of the grit constructs in educational settings. In a previous study, we found that one dimension of grit, perseverance of effort, predicted a variety of educational outcomes, but that its criterion validity could be improved. In this study, we examined if the relationship between perseverance of effort and educational outcomes varied by race, sex, and first-generation status. Understanding how non-cognitive traits like perseverance of effort influence outcomes are critical to their use in educational decisions like admissions. If traits like grit primarily benefit traditional student populations, the use of grit in high stakes decisions could help reproduce inequality and harm non-traditional student populations. However, grit also has the potential to help identify nontraditional students with lower than average academic credentials, but with a high probability of student success.

In our previous work, we demonstrated that grit possesses measurement invariance by race, sex, and first-generation status (Fosnacht et al., 2019). Therefore, grit measures the same construct across these groups, and these groups respond to the grit items similarly. Consequently, 
claims that grit is biased against particular groups seem unfounded (Gonzales-Stokas, 2015; Ris, 2015). However, the research community has not yet explored if the relationship between grit and student outcomes varies across subpopulations. As the perseverance of effort dimension of grit focuses on student resilience in the face of barriers to success or negative experiences, we hypothesised that perseverance of effort would be especially beneficial to the success of nontraditional student populations. If our hypothesis were true, it would indicate that grit is an especially important quality for non-traditional students.

Our results demonstrate that perseverance of effort is significantly and positively related to a variety of student outcomes such as engagement, perceived gains, time spent studying, and GPA. The estimates were uniformly positive, substantial, and broad. A standard deviation change in perseverance of effort was associated with a 0.14 to $0.33 \mathrm{SD}$ change in our dependent variables for first-year students and a 0.11 to 0.25 SD change for seniors. Consequently, perseverance of effort appears to be a factor that leads to engagement in effective educational practices.

Next, we examined if the relationship between perseverance of effort and our dependent variables varied by student characteristics. While the relationship was statistically constant for many dependent variables, we observed 11 situations where the relationship varied significantly by subgroup. A uniform pattern emerged in these significant relationships. The partial correlation between perseverance of effort and our dependent variables was stronger for non-traditional student populations (female, non-White, first-generation) than for traditional students (male, White, non-first-generation). Therefore, the results suggest that perseverance of effort has compensatory effects on important university outcomes. In other words, perseverance of effort helps non-traditional student populations achieve success despite the additional barriers these 
students encounter. Consequently, resilience and overcoming obstacles appear to be particularly salient to the success of non-traditional student populations.

Ajzen’s (1991) Theory of Planned Behavior explains why perseverance of effort may be more salient for marginalised student populations. We conceptualise perseverance of effort as an attitude students use to motivate their desire to engage in educational activities (behavioural intention). Non-traditional students are aware of their marginalised identities (women, firstgeneration, and minorities) and use their identities to motivate their engagement in the behaviour of interest. Students' attitudes are also informed by social pressures from their family and home communities. For example, a first-generation student may feel intense pressure from their family and high school teachers to be successful in university and return to their home community. This pressure may foster resilience to overcome setbacks and inspire students to work harder to achieve a university degree (Bryan \& Simmons, 2009). Consequently, perseverance of effort is particularly important for non-traditional groups. This construct helps students to overcome gaps in college knowledge and push through obstacles inherent in the college-going process.

Our findings have implications for policy and practice. First, our results suggest that an avenue for institutions to close gaps in student success would be to identify and target students who have qualitatively demonstrated traits like perseverance of effort or resilience. We do not recommend using the grit scale to directly identify these students as the scale does not meet accepted psychometric standards for high-stakes decisions and the scale could be "gamed" if students are cognizant of its use in admissions decisions. Second, our findings also suggest that non-traditional students face additional barriers to student success or did not possess the cultural capital specific to postsecondary education needed to navigate higher education. Therefore, nontraditional students required specific non-cognitive attributes to be successful. 
Consequently, higher education institutions should look to proactively identify programs and practices that have a disparate impact on non-traditional students and reformulate them to eliminate their disparate features. Furthermore, institutions should work with faculty, staff, and administrators to ensure that their university is welcoming to all students. While we call for the reduction in barriers to student success for non-traditional students, this call should not be construed as advocating for a less rigorous curriculum or not challenging students academically. Academic challenge is an important aspect of student learning and development and critical to student success.

Our results also have implications for future research. Student engagement is positively related to student persistence and is especially important for historically underrepresented students (Kuh et al., 2006). Therefore, future research should examine the differential impacts of perseverance of effort by student characteristics on persistence. As perseverance of effort has compensatory effects on student engagement and student engagement has compensatory effects on persistence, perseverance of effort is likely to have a larger than average effect on persistence for non-traditional student populations. Our findings also call for continued research into identifying barriers historically underrepresented students face in their pursuit of a degree. While much effort has been given to identifying these barriers, continued vigilance is needed due to the changing nature of higher education. 


\section{References}

Adams, J., \& Corbett, A. (2010). Experiences of traditional and non-traditional college students. Perspectives, 2(1), 2.

Ajzen, I. (1991). The theory of planned behavior. Organizational Behavior and Human Decision Processes, 50(2), 179-211.

Almeida, D. J., Byrne, A. M., Smith, R. M., \& Ruiz, S. (2019). How relevant is grit? The importance of social capital in first-generation college students' academic success. Journal of College Student Retention: Research, Theory \& Practice, 1521025119854688.

Aparicio, M., Bacao, F., \& Oliveira, T. (2017). Grit in the path to e-learning success. Computers in Human Behavior, 66, 388-399.

Bandura, A. (1977). Self-efficacy: toward a unifying theory of behavioral change. Psychological Review, 84(2), 191.

Bazelais, P., Lemay, D. J., \& Doleck, T. (2016). How Does Grit Impact College Students' Academic Achievement in Science?. European Journal of Science and Mathematics Education, 4(1), 33-43.

Blanchard, C., Fisher, J., Sparling, P., Nehl, E., Rhodes, R., Courneya, K., \& Baker, F. (2008). Understanding physical activity behavior in African American and Caucasian college students: an application of the theory of planned behavior. Journal of American College Health, 56(4), 341-346.

Bowman, N.A., Hill, P.L., Denison, N., \& Bronkema, R. (2015). Keep on truckin’ or stay the course? Exploring grit dimensions as differential predictors of educational achievement, 
satisfaction, and intentions. Social Psychology and Personality Science, 6, 639-645. doi: $10.1177 / 1948550615574300$

Bryan, E. \& Simmons, L. A. (2009). Family Involvement: Impacts on Post-secondary Educational Success for First-Generation Appalachian College Students. Journal of College Student Development, 50(4), 391-406.

Burns, M. E., Houser, M. L., \& Farris, K. L. (2018). Theory of planned behavior in the classroom: An examination of the instructor confirmation-interaction model. Higher Education, 75(6), 1091-1108.

Chen, C., Ye, S., \& Hangen, E. (2018). Predicting achievement goals in the east and west: The role of grit among American and Chinese university students. Educational Psychology, $38,820-837$.

Christensen, R., \& Knezek, G. (2014). Comparative measures of grit, tenacity, and perseverance. International Journal of Learning, Teaching and Educational Research, 8(1), 16-30.

Collins, S. E., \& Carey, K. B. (2007). The theory of planned behavior as a model of heavy episodic drinking among college students. Psychology of Addictive Behaviors, 21(4), 498.

Datu, J. F., Valdez, J. P., \& King, R. B. (2015). Perseverance counts but consistency does not! Validating the short grit scale in a collectivist setting. Current Psychology, 35, 121-130. Del Giudice, M. (2014). Grit Trumps Talent and IQ: A Story Every Parent (and Educator) Should Read. Retrieved from http://news.nationalgeographic.com/news/2014/10/141015angela-duckworth-success-grit-psychology-self-control-science-nginnovators/ 
Duckworth, A. L. (2016). Grit: The power of passion and perseverance. Simon and Schuster: New York.

Duckworth, A. L., Peterson, C., Matthews, M. D., \& Kelly, D. R. (2007). Grit: Perseverance and passion for long-term goals. Journal of Personality and Social Psychology, 92(6), 10871101. doi: $10.1037 / 0022-3514.92 .6 .1087$

Duckworth, A.L., \& Quinn, P.D. (2009). Development and Validation of the Short Grit Scale (Grit-S), Journal of Personality Assessment, 9, 166-174. doi:

$\underline{10.1080 / 00223890802634290}$

Engber, D. (2016). Is “Grit” Really the Key to Success? Slate. Retrieved from http://www.slate.com/articles/health_and_science/cover_story/2016/05/angela_duckwort h_says_grit_is_the_key_to_success_in_work_and_life_is_this.html

Eskreis-Winkler, L., Duckworth, A. L., Shulman, E. P., \& Beal, S. (2014). The grit effect: Predicting retention in the military, the workplace, school, and marriage. Frontiers in Psychology, 5, 36.

Fosnacht, K., Copridge, K., \& Sarraf, S. A. (2019). How Valid is Grit in the Postsecondary Context? A Construct and Concurrent Validity Analysis. Research in Higher Education, 60, 803-822. doi: 10.1007/s11162-018-9524-0

Gonzalez-Stokas, A. (2015). A genealogy of grit: Education in the new gilded age. Educational Theory, 65, 513-528. doi: 10.1111/edth.12130

Guerrero, L. R., Dudovitz, R., Chung, P. J., Dosanjh, K. K., \& Wong, M. D. (2016). Grit: a potential protective factor against substance use and other risk behaviors among Latino adolescents. Academic Pediatrics, 16(3), 275-281. 
Harper, S. R., \& Hurtado, H. (2007). Nine themes in campus racial climates and implications for institutional transformation. New Directions for Student Services, 120, 7-24.

Hodge, B., Wright, B., \& Bennet, P. (2017). The role of grit in determining engagement and academic outcomes for university students. Research in Higher Education, 59(4), 448460.

Jaeger, B., Freeman, S., Whalen, R., \& Payne, R. (2010). Successful students: Smart or tough. In Proceedings, ASEE Annual Convention, Paper AC (Vol. 1033).

Kraft, M. A. (in press) Interpreting Effect Sizes of Education Interventions. Educational Researcher.

Kuh, G. D., Kinzie, J., Cruce, T., Shoup, R., \& Gonyea, R. M. (2006, July). Connecting the dots: Multi-faceted analyses of the relationships between student engagement results from the NSSE, and the institutional practices and conditions that foster student success: Final report prepared for Lumina Foundation for Education. Bloomington, IN: Indiana University, Center for Postsecondary Research.

Midkiff, B., Langer, M., Demetriou, C., \& Panter, A. T. (2016, July). Measuring Grit among first-generation college students: A psychometric analysis. In A. van der Ark, M. Wilberg, S. Culpepper, J. Douglas, W. Wang (Eds.) Quantitative Psychology: The $81^{\text {st }}$ Annual Meeting of the Psychometric Society (pp. 407-420). Springer, Cham.

Milem, J. F., Chang, M. J., \& Antonio, A. L. (2005). Making diversity work on campus: A research-based perspective. Washington, DC: Association American Colleges and Universities.

Nakagawa, S. (2004). A farewell to Bonferroni: The problems of low statistical power and publication bias. Behavioral ecology, 15(6), 1044-1045. 
National Survey of Student Engagement. (n.d.). Validity: 2009 Known Groups Validation. Retrieved from http://nsse.indiana.edu/pdf/psychometric_portfolio/Validity_GroupMembership.pdf.

National Survey of Student Engagement. (n.d.). Validity: Predicting retention and degree progress. Retrieved from http://nsse.indiana.edu/pdf/psychometric_portfolio/PredictiveValidity_retention_degreepr ogress.pdf

O’Neal, C. R., Espino, M. M., Goldthrite, A., Morin, M. F., Weston, L., Hernandez, P., \& Fuhrman, A. (2016). Grit under duress: Stress, strengths, and academic success among non-citizen and citizen Latina/o first-generation college students. Hispanic Journal of Behavioral Sciences, 38, 446-466. doi: 10.1177/0739986316660775

Pascarella, E. T., Seifert, T. A., \& Blaich, C. (2010). How effective are the NSSE benchmarks in predicting important educational outcomes?. Change: The Magazine of Higher Learning, $42(1), 16-22$.

Pelling, E. L., \& White, K. M. (2009). The theory of planned behavior applied to young people's use of social networking web sites. CyberPsychology \& Behavior, 12(6), 755-759.

Perneger, T. V. (1998). What's wrong with Bonferroni adjustments. BMJ, 316(7139), 1236-1238.

Ris, E. W. (2015). Grit: A short history of a useful concept. Journal of Educational Controversy, 10(1), Article 3. Retrieved from http://cedar.wwu.edu/cgi/viewcontent.cgi?article=1246\&context=jec.

Shechtman, N., DeBarger, A., Dornsife, C., Rosier, S., \& Yarnall, L. (2013). Promoting Grit, Tenacity, and Perseverance: Critical Factors for Success in the 21st Century. US 
Department of Education Office of Educational Technology. Retrieved from: www.ed.gov/edblogs/technology/files/2013/02/OET-Draft-Grit-Report-2-17-13. pdf.

Siragusa, L. \& Dixon, K. (2009). Theory of planned behaviour: Higher education students' attitudes towards ICT-based learning interactions. In Same places, different spaces. Proceedings ascilite Auckland 2009. http://www.ascilite.org.au/conferences/auckland09/procs/siragusa.pdf

Slick, S. N., \& Lee, C. S. (2014). The relative levels of grit and their relationship with potential dropping-out and university adjustment of foreign students in Korea. Journal of Digital Convergence, 12(8), 61-66.

Strayhorn, T. L. (2014). What role does grit play in the academic success of Black male collegians at predominately-white institutions?. Journal of African American Studies, 18, 1-10. doi: 10.1007/s12111-012-9243-0.

Turner, C. S. V., González, J. C., \& Wood, J. L. (2008). Faculty of color in academe: What 20 years of literature tells us. Journal of Diversity in Higher Education, 1(3), 139-168. doi: $10.1037 / \mathrm{a} 0012837$

Vela, J. C., Lu, M. T. P., Lenz, A. S., \& Hinojosa, K. (2015). Positive psychology and familial factors as predictors of Latina/o students' psychological grit. Hispanic Journal of Behavioral Sciences, 37(3), 287-303.

Verdín, D., Godwin, A., Kirn, A., Benson, L., \& Potvin, G. (2018). Understanding how engineering identity and belongingness predict grit for first-generation college students. In 2018 CoNECD - The Collaborative Network for Engineering and Computing Diversity Conference. Retrieved from https://www.asee.org/public/conferences/113/papers/24218/download 
Weisskirch, R. S. (2018). Grit, self-esteem, learning strategies and attitudes and estimated and achieved course grades among college students. Current Psychology, 37(1), 21-27.

Wolters, C. A., \& Hussain, M. (2015). Investigating grit and its relations with college students' self-regulated learning and academic achievement. Metacognition and Learning, 10(3), 293-311. doi: 10.1007/s11409-014-9128-9

Yates III, L., Moore, J., Vairez Jr, M. R., Barber-Freeman, P. T., Ross, W., Parker, W. H., \& Bautista, R. (2015). The Grit of African American Male Pre-Service Teachers. Journal of the Texas Alliance of Black School Educators The Grit of African American, 1(2), 1138.

Zhang, M., Mou, N., Tong, K., \& Wu, A. (2018). Investigation of the effects of purpose in life, grit, gratitude, and school belonging on mental distress among Chinese emerging adults. International journal of environmental research and public health, 15(10), 2147. 
Table 1.

Relationship between perseverance of effort and student engagement, perceived gains, time spent preparing for class, and GPA

\begin{tabular}{|c|c|c|c|c|c|c|c|c|}
\hline \multirow[b]{2}{*}{ Dependent variable } & \multicolumn{4}{|c|}{ First-year } & \multicolumn{4}{|c|}{ Senior } \\
\hline & Coef. & SE & Sig. & $\mathrm{R}^{2}$ & Coef. & $\mathrm{SE}$ & Sig. & $\mathrm{R}^{2}$ \\
\hline Higher-Order Learning & 0.24 & 0.02 & .000 & .09 & 0.16 & 0.02 & .000 & .08 \\
\hline Reflective \& Integrative Learning & 0.21 & 0.02 & .000 & .11 & 0.15 & 0.02 & .000 & .16 \\
\hline Quantitative Reasoning & 0.19 & 0.02 & .000 & .08 & 0.14 & 0.02 & .000 & .13 \\
\hline Learning Strategies & 0.33 & 0.02 & .000 & .13 & 0.23 & 0.02 & .000 & .13 \\
\hline Collaborative Learning & 0.16 & 0.02 & .000 & .08 & 0.13 & 0.02 & .000 & .14 \\
\hline Discussions w/ Diverse Others & 0.14 & 0.02 & .000 & .07 & 0.14 & 0.02 & .000 & .07 \\
\hline Student-Faculty Interaction & 0.18 & 0.02 & .000 & .07 & 0.16 & 0.02 & .000 & .12 \\
\hline Quality of Interactions & 0.17 & 0.02 & .000 & .07 & 0.11 & 0.02 & .000 & .05 \\
\hline Supportive Environment & 0.21 & 0.02 & .000 & .06 & 0.14 & 0.02 & .000 & .06 \\
\hline Perceived gains & 0.28 & 0.02 & .000 & .10 & 0.17 & 0.02 & .000 & .10 \\
\hline Time spent: Preparing for class & 0.19 & 0.02 & .000 & .08 & 0.19 & 0.02 & .000 & .10 \\
\hline GPA & 0.28 & 0.02 & .000 & .18 & 0.25 & 0.02 & .000 & .23 \\
\hline
\end{tabular}

Note: The dependent variables and perseverance of effort were standardised with a mean of 0 and a standard deviation of 1. Models controlled for race/ethnicity, sex, age, parental education, SAT I or ACT equivalent, student-athlete status, enrollment intensity, greek-life participation, transfer status, living on campus, and major field. Models also included institution-specific fixed effects. $\mathrm{R}^{2}$ is for the full model including all covariates. 
Table 1.

Significance tests associated with the interaction term coefficient between perseverance of effort and student characteristics, by race, sex, and parental education and class standing

\begin{tabular}{|c|c|c|c|c|c|c|}
\hline & \multicolumn{3}{|c|}{ First-year } & \multicolumn{3}{|c|}{ Senior } \\
\hline & \multirow[b]{2}{*}{ Race } & \multicolumn{2}{|r|}{ Par. } & \multirow[b]{2}{*}{ Race } & \multirow{2}{*}{\multicolumn{2}{|c|}{$\begin{array}{l}\text { Par. } \\
\text { Ed }\end{array}$}} \\
\hline & & Sex & Ed. & & & \\
\hline Higher-Order Learning & 0.841 & 0.003 & 0.051 & 0.072 & 0.362 & 0.178 \\
\hline Reflective \& Integrative Learning & 0.414 & 0.826 & 0.035 & $\mathbf{0 . 0 3 8}$ & 0.227 & 0.104 \\
\hline Quantitative Reasoning & 0.605 & 0.677 & 0.426 & 0.049 & 0.196 & 0.214 \\
\hline Learning Strategies & 0.222 & 0.153 & 0.098 & 0.773 & 0.615 & 0.168 \\
\hline Collaborative Learning & 0.219 & 0.195 & 0.998 & 0.151 & 0.060 & 0.406 \\
\hline Discussions w/ Diverse Others & 0.042 & 0.891 & 0.143 & 0.017 & 0.188 & 0.135 \\
\hline Student-Faculty Interaction & 0.506 & 0.565 & 0.303 & 0.168 & 0.002 & 0.020 \\
\hline Quality of Interactions & 0.060 & 0.705 & 0.589 & 0.397 & 0.373 & 0.526 \\
\hline Supportive Environment & 0.117 & 0.945 & 0.456 & 0.951 & 0.099 & 0.050 \\
\hline Perceived gains & 0.775 & 0.218 & 0.198 & 0.174 & 0.187 & 0.062 \\
\hline Time spent: preparing for class & 0.279 & 0.013 & 0.560 & 0.532 & 0.787 & 0.897 \\
\hline GPA & 0.842 & 0.199 & 0.025 & 0.188 & 0.409 & 0.057 \\
\hline
\end{tabular}

Note: Models controlled for race/ethnicity, sex, age, parental education, SAT I or ACT equivalent, student-athlete status, enrollment intensity, greek-life participation, transfer status, living on campus, and major field. Models also included institution-specific fixed effects. 
Figure 1.

Selected interaction effect results by outcome for race: First-year students

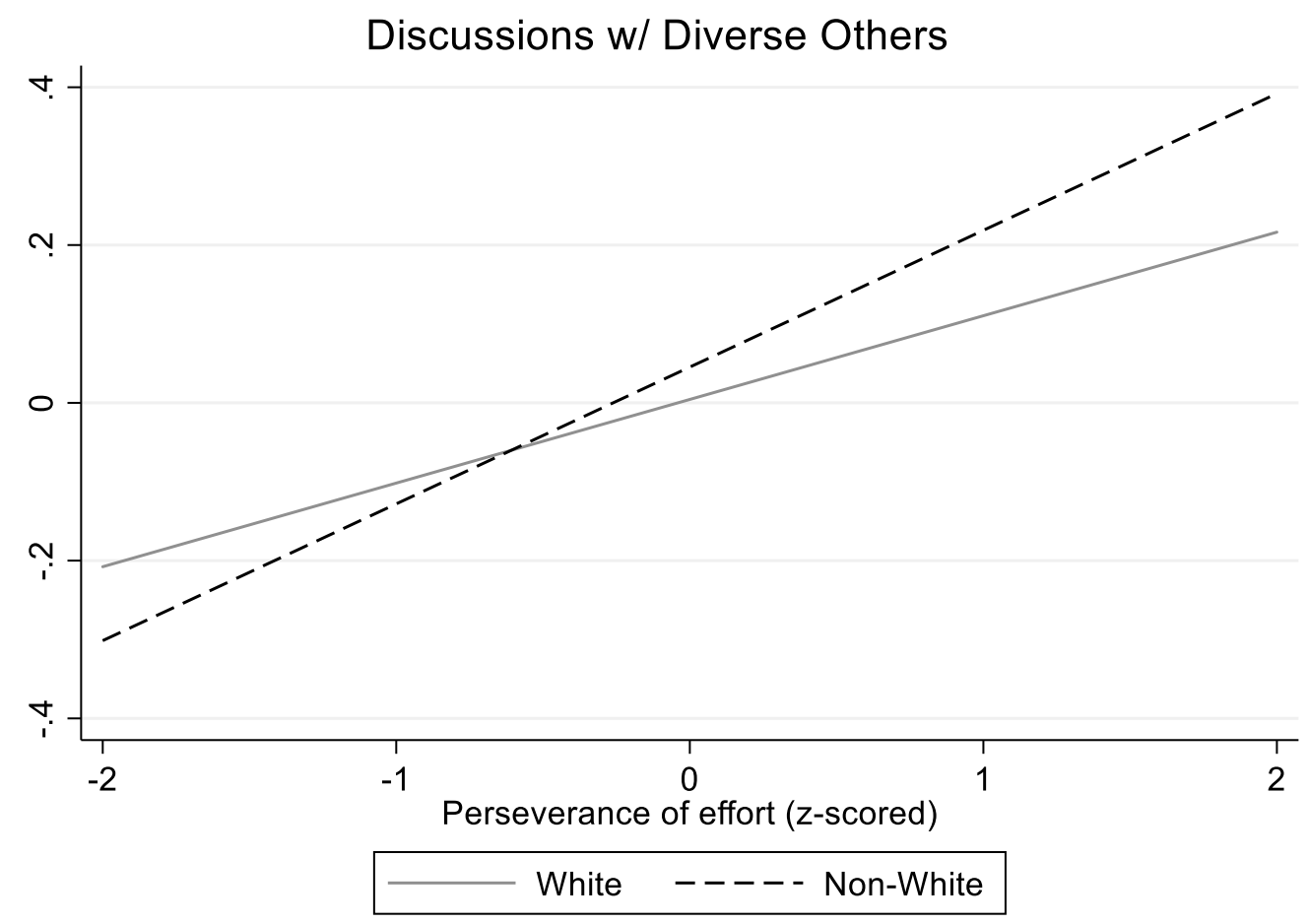


Figure 2 .

Selected interaction effect results by outcome for sex: First-year students

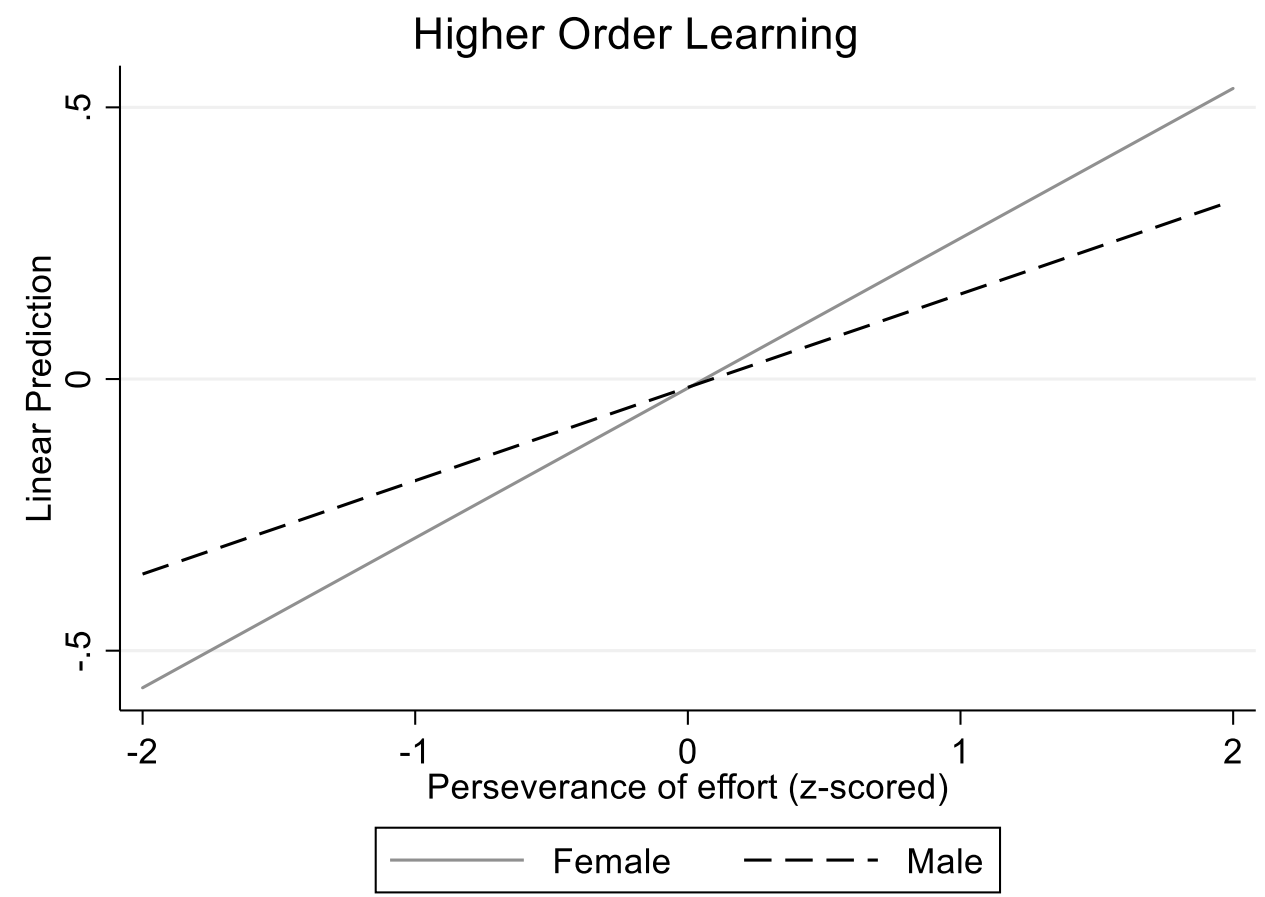

Time: Preparing for class

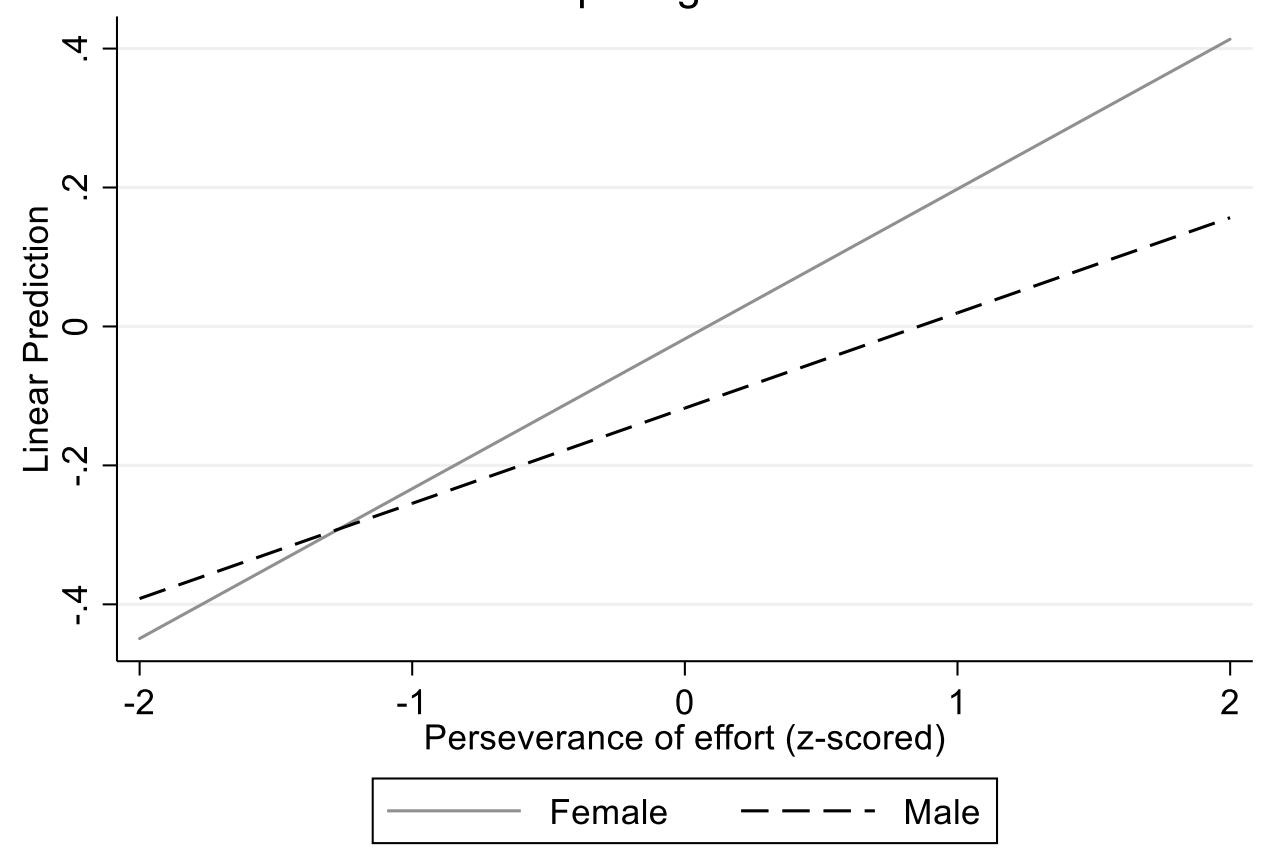


Figure 3.

Selected interaction effect results by outcome for parental education: First-year students
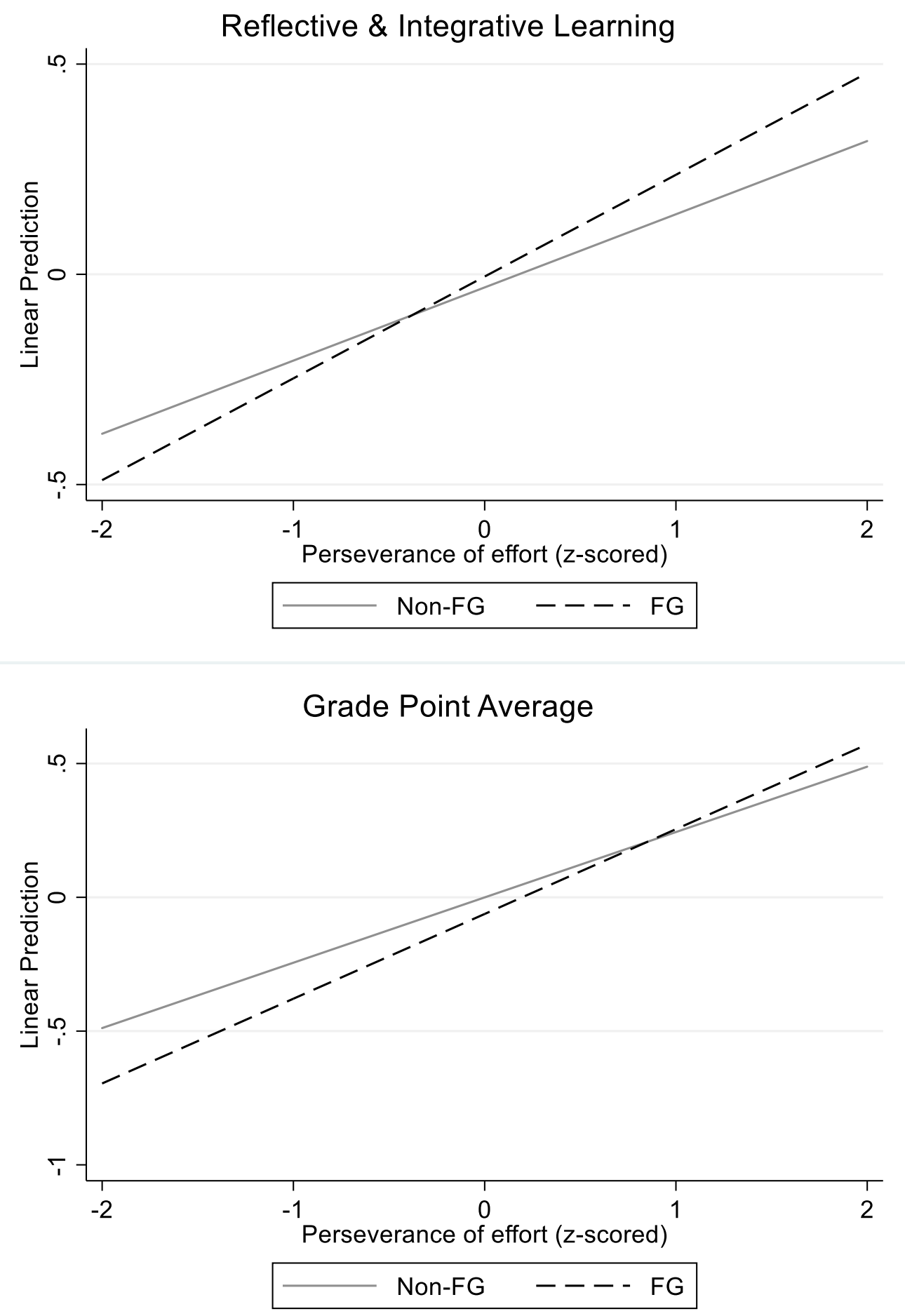
Figure 4.

Selected interaction effect results by outcome for race: Seniors
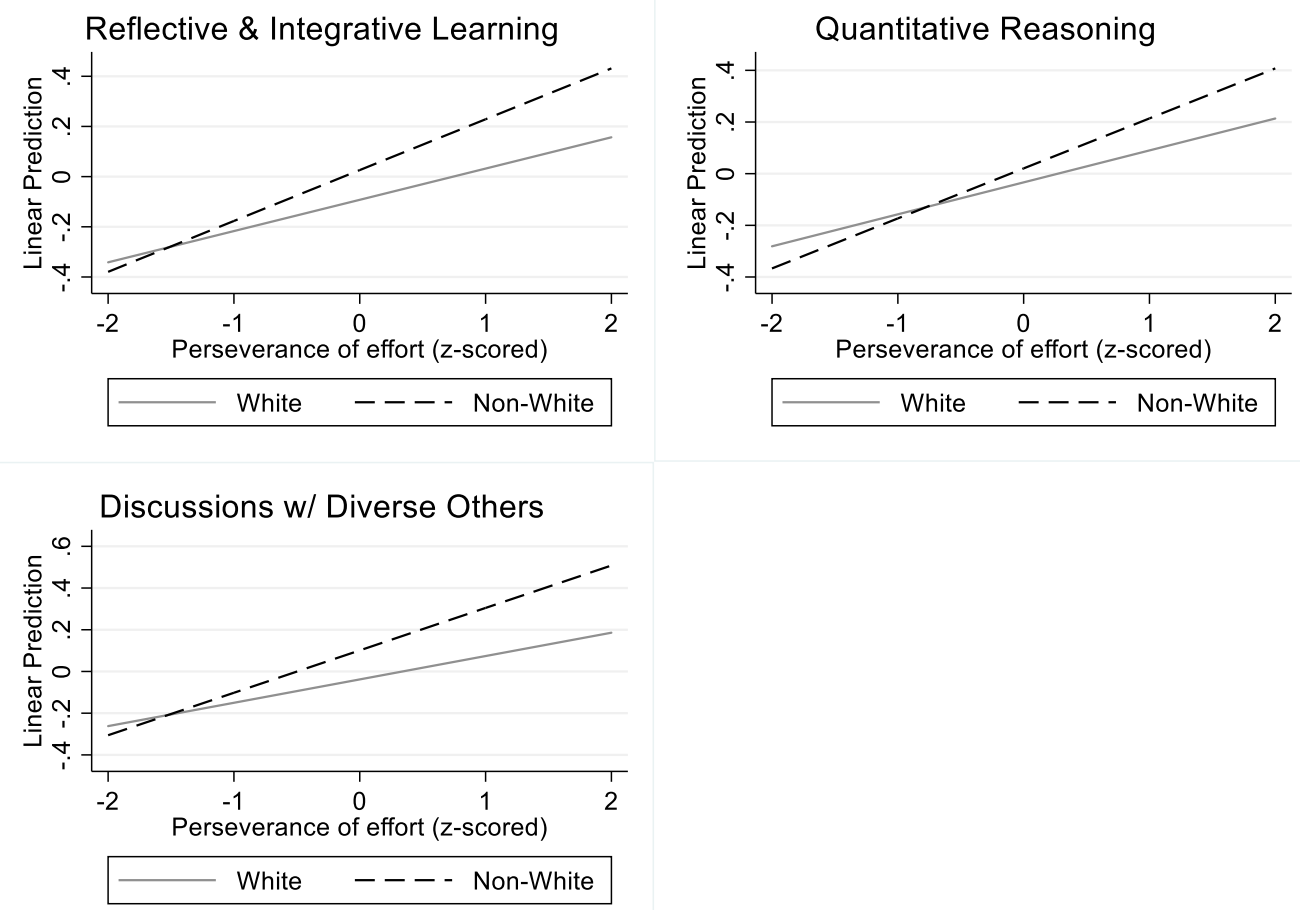
Figure 5.

Selected interaction effect results by outcome for sex: Seniors

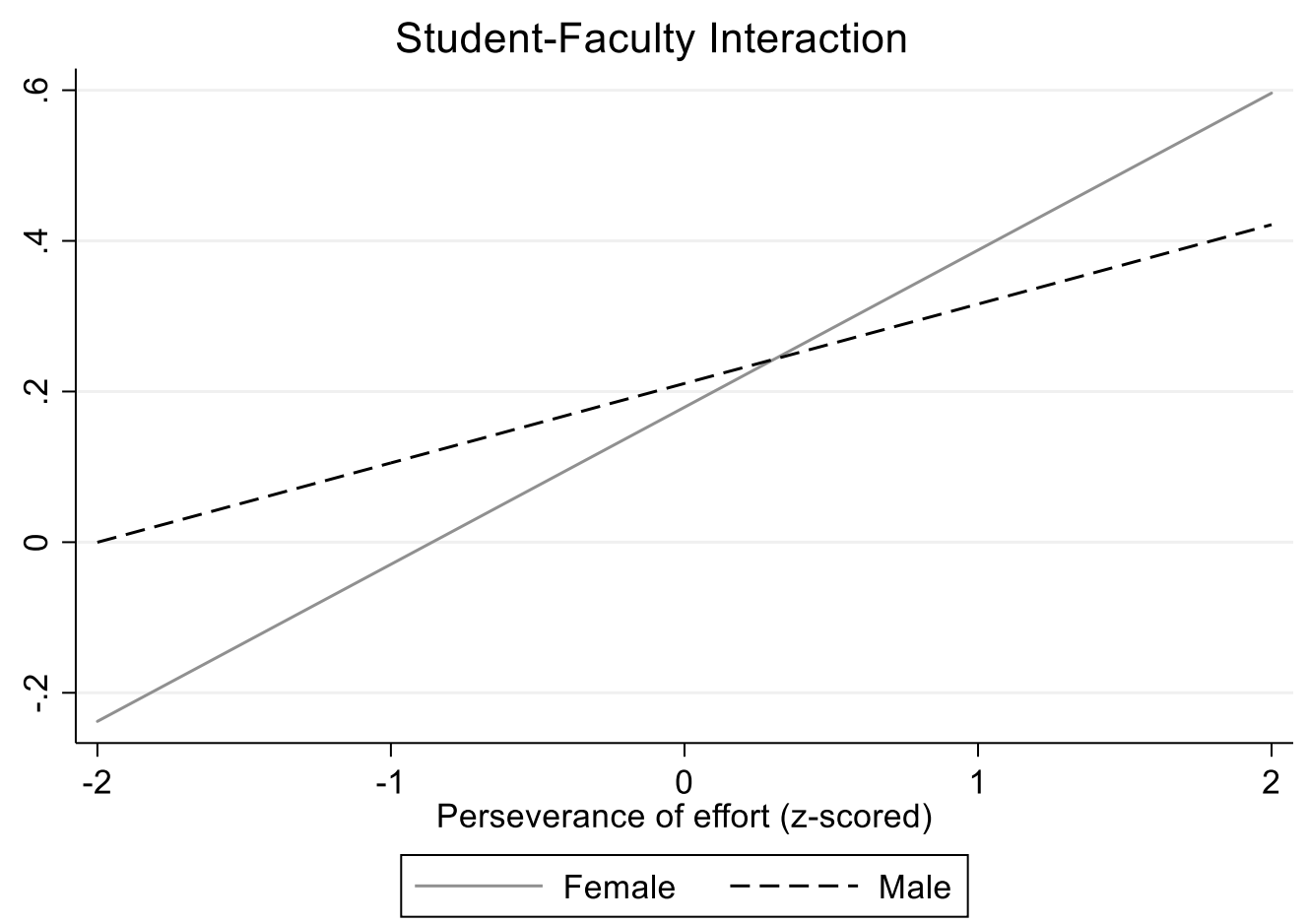


Figure 6.

Selected interaction effect results by outcome for parental education: Seniors
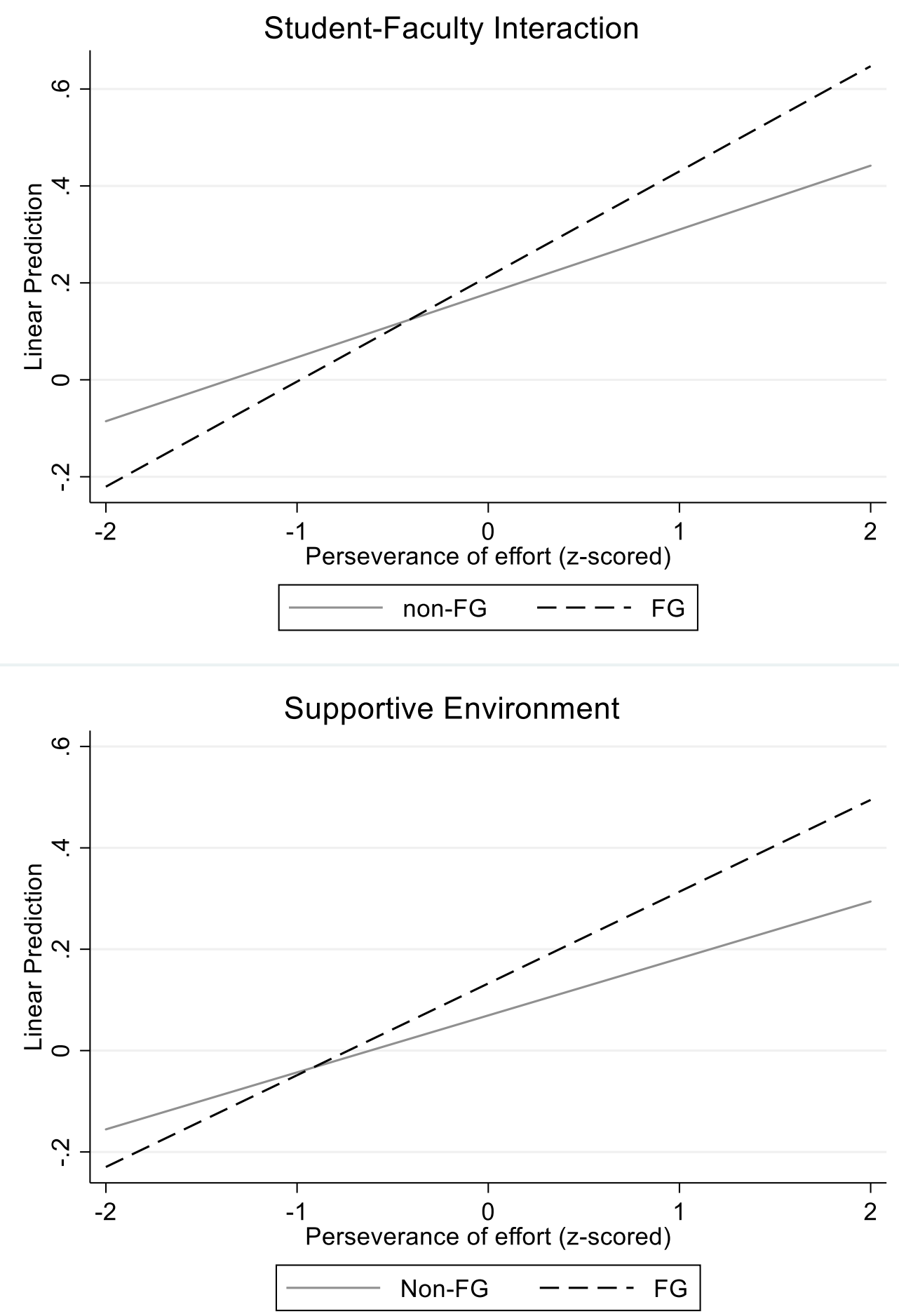